\title{
A review on preparation methods of SNPs and their biomedical applications
}

\author{
Khatoon UT*, Mohan MK and Rao GVSN \\ Metallurgical and Materials Engineering Department, National Institute of Technology, Warangal-506004, Telangana state, India
}

\begin{abstract}
Researchers have identified Silver Nano Particles (SNPs) as a key area of interest because of their unique shape and size dependent biomedical properties. They have discovered and invented a variety of methods for the synthesis of SNPs such as microwave irradiation techniques, laser ablation synthesis, biological synthesis, photochemical synthesis and chemical synthesis etc. In this review paper we overview the preparation of SNPs through various synthesis methods and also their applications in the bio-medical field. The main aim of this paper is to keep up to date with the myriad ongoing synthesis methods of synthesis of NPs and also examine their applications especially in the field of medicine.
\end{abstract}

\section{Silver Nano Particles (SNPs)}

Silver (Ag) is a white colored, lustrous looking, physically soft, transition element metal having high thermal and electrical conductivity. It has been used by humans earlier than the recorded history due to its ornamental, medical and therapeutic benefits even before realizing that microbes are the causative agents of infections. It is used by people in many forms such as solutions, foils, coins, vessels, sutures, and in colloids such as lotions, ointments etc. It is one of the most prominent therapeutic elemental agent in medicine for surgical infections and infectious diseases. The tangible advantages of silver have a bigger weightage than the intangible risk factors [1].

Nanoscience is a novel multidisciplinary subject that depends on the basic physical and chemical properties displayed by nano level objects $[2,3]$. Nanoparticles have been shown to display amazing electromagnetic, surface optical and chemically catalytic characteristics than the macro bulk material owing to their extremely low volume to surface area ratio [4,5]. Metal nanoparticles such as silver show different colors due to their Surface Plasmon Resonance (SPR) phenomenon. It is a group oscillatory behavior of the free electrons of the metal nanoparticles having the same frequency of the light wave interactions, resulting in resonance, causing the SPR band to form in the infrared and visible region [6]. Nanoparticles, especially the metallic ones, whose production can be done through various methods, the usual ones being physical and chemical methods. The above-mentioned methods produce high purity, well-defined nanoparticles, but the reagents used in the synthesis are hazardous, energy consuming, expensive, toxic and not suitable for physiological or ecological applications. Research regarding the synthesis of metal nanoparticles was extensively covered in the past three decades, but research of nanosynthesis, based on plant extracts, bloomed only in the last ten years [7-13].

Silver nanoparticles are finding themselves in the limelight due to their biological, chemical and physical properties that contributes to the bactericidal and fungicidal effects, catalytic activity and finds applications in nanobiotechnological research [14,15]. Doctors are beginning to use them in wound dressings as anti-microbial agents, in topically applied creams used to prevent wound infections, and even finds success in use as anticancer applications [16-20].

\section{Preparation of SNPs}

Different strategies are used for the preparation of nano structures that are mostly metal, that should be usually controllable regarding their shape and size, high yield with less waste of products, cost effectiveness and environment friendliness. Figure 1, Comprises of various planning methodologies for SNPs. Metal nano structures exhibit huge abundance of plasmon excitations for example researchers are now showing increased interest in SNPs due to this phenomenon, which is in the range of visible spectrum and has been marked for potential use in many future technologies. Here, this paper will examine all the most reference synthetic processes involved in metal nanoparticle preparations, especially that of silver (Ag).

\section{Chemical reduction synthesis}

One among the most frequently used processes is the technique of chemical reduction used to synthesize SNPs using organic and inorganic reducing agents. Different reducing agents like tri sodium citrate, sodium borohydride, ascorbic acid etc are used in reducing Silver ions (Ag+) to metallic Silver (Ago) after which cluster formation takes place. Therefore, colloidal SNPs are formed from the aforementioned clusters in aqueous or non-aqueous solutions.

Research has found that it is necessary to use agents of protective nature to stabilize nanoparticles during the process of formation and that these agents protect them by being absorbed or bound to the NPs

Correspondence to: Umme Thahira Khatoon, Metallurgical and Materials Engineering Department, National Institute of Technology, Warangal-506004, Telangana state, India; Tel: +91-870-2459547; E-mail: ummethahirakhatoon@ gmail.com

Key words: Silver Nano Particles (SNPs), Bio-medicine, Citrate synthesis method, Anticancer drug

Received: June 20, 2017; Accepted: July 24, 2017; Published: July 27, 2017 


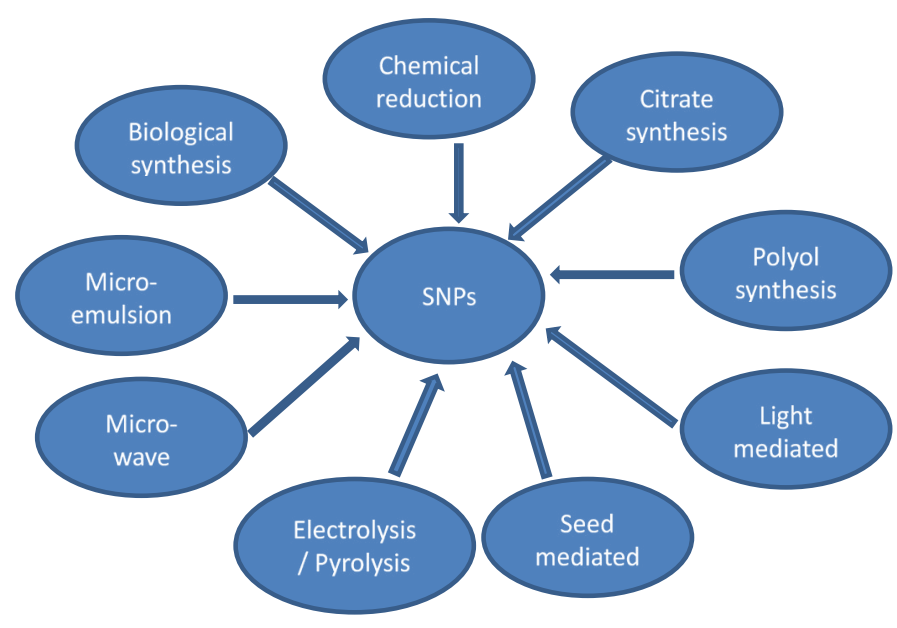

Figure 1. Various planning methodologies for synthesis of SNPs.

surfaces preventing their clustering. The existing compounds that lower surface tension are termed as surfactants, these have a stabilizing effect which comprises characteristic abilities to stabilize particle growth, meanwhile reacting with the particulate surface. Using these fortifying agents protects the particles from clustering and helps to preserve their shape and size and from the loss of particles surface properties.

The shape and size of the metal nanoparticles critically determine the optical characteristics. The one of a kind plasmonic characteristics of metal nanoparticles are largely influenced by the controlled morphology. So far, different techniques have been tried and adopted for the production of these NPs with controlled shape and size [2123]. Usually, the initial form of silver ion $\left(\mathrm{Ag}^{+}\right)$is mixed with reducing agents while in the vicinity of a fortifying agent which controls the shape and size of the metal NPs. Previous scientific research has shown that the preferred precursor is silver nitrate and has been broadly used because of its easy accessibility and affordability. There are myriad reducing agents that are abundantly used to reduce silver ions $\left(\mathrm{Ag}^{+}\right)$present in the solution to individual silver atoms which come together to form agglomerates and consequently become SNPs [2425] Meanwhile, fortifying agents are added to stabilize and control the desired morphology of SNPs.

$\mathrm{N}_{2} \mathrm{H}_{4}$ can reduce silver nitrate $\left(\mathrm{AgNO}_{3}\right)$ through a one pot technique of reduction in presence of water $\left(\mathrm{H}_{2} \mathrm{O}\right)$ and sodium ethanoate $\left(\mathrm{CH}_{3} \mathrm{COONa}\right)$ at $250^{\circ} \mathrm{C}$ for $120-180$ minutes with water as the solvent being utilized [26]. The creation of SNPs (4-8 nm) with size as the regulation parameter was done using a modified version of silver perchlorate $\left(\mathrm{AgClO}_{4}\right)$ which was reduced by sodium borohydride $\left(\mathrm{NaBH}_{4}\right)$ without using any agents to stabilize [27]. The time duration of synthesis within $24-48$ hours was found to be a major factor in determining the size of SNPs mediated by polyethylene glycol and along with the use of $\beta-D$-glucose at $450^{\circ} \mathrm{C}$ [28]. The chitosan stabilized SNPs have been produced using $\gamma$ - rays.

\section{Citrate reduction synthesis}

A frequently used method for preparing silver colloidal solutions is citrate reduction of silver $\left(\mathrm{Ag}^{+}\right)$ions because it doesn't require intense laboratorial skills [29-31]. This method was first introduced in 1982 by Lee and Meisel [32]. In this method SNPs are created when a predetermined amount of sodium citrate is put in a liquid state solution of silver nitrate $\left(\mathrm{AgNO}_{3}\right)$ which was boiling and kept for a minimum of 60 minutes. Though this method is quite easy it didn't result in regulated size of NPs. The final product exhibited a very broad range of size from $20-600 \mathrm{~nm}$. Nevertheless, $\mathrm{pH}$ regulation is a critical factor, since only little shape controlled techniques had been examined by earlier researchers by regulating $\mathrm{pH}$ with values such $\mathrm{pH}=11.1$ for spherical shape and rod like particles and $\mathrm{pH}=5.7$ for a triangular shape $[33,34]$.

\section{Polyol synthesis}

A broadly well-known and frequently used technique to synthesise broad range of SNPs [35-39]. Usually, the creation of nucleation and growth towards SNPs happens because of the introduction of silver salt capping agents and precursors. The silver $\left(\mathrm{Ag}^{+}\right)$ions found in the solution are reduced by the commonly used reducing agents such as 1 , 2-propylene glycol, 1,5-pentanediol or propylene glycol. The probable regulation on the ultimate reaction product is influenced by reaction variables such as concentration and temperature.

\section{Light mediated synthesis}

NPs are manufactured by the application of light irradiation in this method. With the source of light acting as a reducing agent, a direct laser irradiation or ablation was conducted on the metal salt solution in aqueous form with the surfactant present to fabricate the size and shape spread of SNPs [40,41]. This coherent light sources is also used to change the metal nanostructures by causing the silver nanospheres to melt into silver nanoplates [42-47]. This method is called as tailoring with light. So far, researchers have had great success for producing good, really desirable and properly regulated SNPs.

\section{Seed mediated synthesis}

Over the previous decade another method that is gaining a lot attraction to produce silver nano particles is seed assisted synthesis where nano crystals function as seeds for future growth. The advantages of this technique over final product morphology is profound [48-51]. For instance, Xia et al created, in 2010, silver nano tubes by making use of cubic or spherical shape single crystal seed for a particular length of edge ranging from $30-200 \mathrm{~nm}$.

\section{Electrolysis and pyrolysis synthesis}

From the analysis of literature it was found that only a few scientific reports available explaining the usage of electro-chemical technique for the production of SNPs. As an example, silver ions $\left(\mathrm{Ag}^{+}\right)$were reduced with polyvinyl pyrolydone present using electrochemical technique, with platinum plate of $1 \mathrm{~cm}$ radius working as anode and titanium electrode working as cathode to produce silver (Ag) NPs which were in spherical in shape. There exists another method comprising of spray pyrolysis for which an average grain size of $100 \mathrm{~nm}$ of silver nano powder was found in the synthesis. Of many synthesis processes, electrolysis and pyrolysis methods are judged to be eco-friendly as there is no toxic or hazardous reducing agents involved in the production of these NPs [52,53].

\section{Microemulsion synthesis}

Homogenous regulation adhering SNPs can be created using micro emulsion method. The special separation of reducing agent and silver precursor in two phases that cannot be mixed at the start of process is the basis for the SNP preparation in two phase aqueous system that is organic. The rate of interaction amongst reducing agent and silver precursor is affected by the interface between the two solutions and the strength of interface movement between two phases, which is the process assisted by alkali ammonium quaternary salt. The surface of the SNPs being covered with stabilizer molecule which happen to be found non-polar liquid solution and moved to the organic medium with the 
help of the inter-phase transporter results in the silver cluster forming at the inference to be stabilized [54]. Greatly hazardous organic solvents being utilized is one of the major drawbacks.

The end product must be bereft of these solvents and huge amounts of surfactants by segregation. For example, Matin et al., [55] found that there was no requirement to segregate the prepared, from the reaction mixture when they utilized dodecace as the oily phase. The surface of polymeric substrate was wetted without any clustering by colloidal SNPs made in non-aqueous media because conductive things are distributed quite well in a low gaseous pressure organic solvent. These organic reactions that have been conducted in non-polar solvents are best catalyzed by the beneficial applications of SNPs as catalyst. During practical applications, these SNPs are supposed to be moved to variety of physicochemical changes as one of the main criteria [56].

\section{Microwave-assisted synthesis}

A method with good prognosis for creation of SNPs is microwaveassisted synthesis. Studies have shown that this method consistently yields SNPs with narrower size distribution, higher degree of crystallization and smaller sizes as compared to conventional oil baths [57]. Along with the prevention of the clustering of NPs formed microwave heating has reduced energy usage, greater product yields and shorter time of production [57]. This technique with help from non-hazardous media eliminates the usage of oil baths tremendously decreases the chemical waste and time duration of reaction in many chemical alterations and many organic syntheses [58]. Carboxymethylselilo sodium can be used as a stabilizing and reducing agent for the synthesis of SNPs by this process route. There were no visible variations noticed and the so produced SNPs were stable and uniform at room temperature for 2 months [59]. It was also reported that there was the creation of ethylene glycol and polyvinyl pyrrolidine in the presence of platinum seeds [60].

\section{Biological synthesis}

It has been found from recent research that microbes such fungi, bacteria and certain algae have great capability for the synthesis of metal Nps such as Cadmium Sulphide (CdS), Silver (Ag), Zirconia $\left(\mathrm{ZrO}_{2}\right)$, Gold (Au), Titanate, Titanium (Ti)/Nickel (Ni) [61-67]. This method provides good regulation over size spread of nanoparticles and is also an eco-friendly and non-hazardous process route for production NPs. For instance, less than $200 \mathrm{~nm}$ sized NPs of silver (Ag) were produced using bacteria.

\section{Applications of SNPs in medical biology}

SNPs has found increasing use as an attractive application for medical requirements because of their exclusive characteristics like their quantum properties, good surface to mass ratio which is greater than that of other particles and the capability to adsorb and transport other compounds such as proteins, drugs and probes. The field of NPs is being explored continuously in an exponential manner and it is amazing to find that SNPs are receiving the greatest amount of attention. This is inparticular due to huge utilization in electronics, photonics, sensing, catalysis, imaging, drug delivery and environmental cleanup [68-70]. Figure 2. presents the various applications of SNPs in the field of biomedicine.

\section{Catalysis}

The usage of nanoparticles as catalyst is a quickly growing field in nanoscience and technology. The characteristics of noble SNPs make

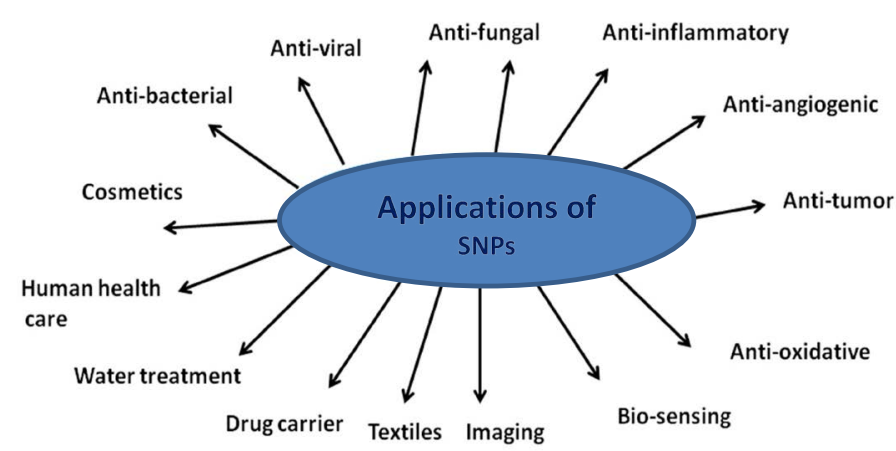

Figure 2. List of applications of SNPs in the field of Biomedicine.

them the best materials for nano-catalysis. Especially where selectivity and reaction yield depend on the properties of catalyst surface. They exhibit greater turnover frequencies as compared to bulk materials because of lower volume to surface area ratio. For instance, we know that in the decomposition of hydrogen peroxide to Oxygen the catalytic properties of Silver are quite useful. In addition, noble metals are also involved in catalysis of luminal hydrogen peroxide systems. It was seen that the addition of silver, gold colloid highly improved the chemiluminescence emission coming from luminal $\mathrm{H}_{2} \mathrm{O}_{2}$ systems [71]. Also popular is the utilization of silver in the catalysis of ethylene oxide from oxidation of ethylene and formaldehyde from oxidation of methanol. But, something that piques greater interest is that the nanoparticles show shaped regulated catalytic activity. When benzene hydrogenation occurs in the presence of platinum catalyst we can notice shape regulated catalytic characteristics [72].

\section{Drug delivery}

Many researchers are of the opinion that SNPs are ideal for drug delivery scaffold because of its non-immunogenicity and its nontoxicity. It is also marked as a viable vehicle for drug delivery because of its functionalization property. It was found that this mechanism released of multiple drugs in a well-regulated manner. These researchers also showed that nanoparticles of various shapes react to different infrared frequencies [73].

\section{Cancer therapy}

As we have already seen nanotechnology is a raising favorite in popular research segments, particularly with respect to bio-medical applications. Targeted drug treatments have been marked as good opportunity for metal NPs specially SNPs [74]. Their potential has also been identified in the areas of time-release and targeted medications. For instance, a powerful dose of drug can be engineered to be delivered to a particular area while also controlling the release over a specific duration to maximize the effectiveness and ensure patient safety. Since, the absorbed energy from light is radiated into the vicinity of these particles resulting in an increased temperature in their surroundings, making the strong light absorbing SNPs formidable heat mediating objects the application of this characteristic is quite potent as it can be utilized to open polymer micro capsules and good potentially eliminate the cancerous cells as well. It is theorized that these nanoparticles if functionalized with the anti-body designed to target the cancerous cells can be quite effective. Such functionalized NPs particularly bind with the targeted cells which are then destroyed by hyper-thermal therapy through heating the particle ordered tissue. Yet the grey area that remains for such in vivo applications is the probable cytotoxicity of the nanoparticles is a potential danger and must undergo careful investigations. Since, $\mathrm{Ag}$ has been found to be non-poisonous and 
bio-compatible they do find huge utilization in the elimination of malignant cancerous cells these days [75].

\section{Conclusion}

Metal NPs especially silver (Ag) have generated a lot of interest in multiple areas such as nanotechnology, electronics, catalysis, optics, biotechnology, textile engineering, water treatment and bio-medicine. By adjusting the conditions of reaction such as stabilizer, reducing agent and also employing various synthetic methods we can regulate the size, shape and size distribution of SNPs. It is therefore quite important to explain the effects of the condition of reaction on the size of NPs and their morphology as well. Other important parameters in the evaluation of NPs synthesis include particle shape and size and mono dispersity. Hence, it is suggested that efficient regulation on the morphology and mono dispersity of these particles must be researched. The goal being to optimization of reaction conditions. Thus we have seen that there are synthesis techniques that can produce well characterized NPs faster than physical or chemical approaches. These environmental friendly techniques can potentially be utilized in a wide variety of areas including cosmetics, pharmaceuticals, medical applications and foods.

\section{Conflict of interest}

The authors declare that there is no conflict of interest.

\section{References}

1. Hadrup N, Lam HR (2014) Oral toxicity of silver ions, silver nanoparticles and colloidal silver--a review. Regul Toxicol Pharmacol 68: 1-7. [Crossref]

2. De Faria AF, Martinez DS, Meira SM, de Moraes AC, Brandelli A, et al. (2014) Antiadhesion and antibacterial activity of silver nanoparticles supported on graphene oxide sheets. Colloids and Surfaces B: Biointerfaces 113: 115-124.

3. Prabhu S, Poulose EK (2012) Silver nanoparticles: mechanism of antimicrobial action, synthesis, medical applications, and toxicity effects. International Nano Letters 2: 32.

4. Mahapatro A (2015) Bio-functional nano-coatings on metallic biomaterials. Mater Sci Eng C Mater Biol Appl 55: 227-251. [Crossref]

5. Ghaffari-Moghaddam M, Hadi-Dabanlou R (2014) Plant mediated green synthesis and antibacterial activity of silver nanoparticles using Crataegus douglasii fruit extract. Journal of Industrial and Engineering Chemistry 20: 739-744.

6. Mittal AK, Chisti Y, Banerjee UC (2013) Synthesis of metallic nanoparticles using plant extracts. Biotechnology Advances 31: 346-356.

7. Ghaffari-Moghaddam M, Hadi-Dabanlou R, Khajeh M, Rakhshanipour M, Shameli K (2014) Green synthesis of silver nanoparticles using plant extracts. Korean Journal of Chemical Engineering 31: 548-557.

8. Faramarzi MA, Sadighi A (2013) Insights into biogenic and chemical production of inorganic nanomaterials and nanostructures. Advances in Colloid and Interface Science 189: $1-20$.

9. Kumari B, Sharma S, Singh N, Verma A, Satsangi VR, et al. (2014) ZnO thin films, surface embedded with biologically derived $\mathrm{Ag} / \mathrm{Au}$ nanoparticles, for efficient photoelectrochemical splitting of water. International Journal of Hydrogen Energy 39: 18216-29.

10. Azizi S, Ahmad MB, Namvar F, Mohamad R (2014) Green biosynthesis and characterization of zinc oxide nanoparticles using brown marine macroalga Sargassum muticum aqueous extract. Materials Letters 116: 275-277.

11. Das R, Nath SS, Bhattacharjee R (2011) Luminescence of copper nanoparticles. Journal of Luminescence 131: 2703-2706.

12. Patel V, Berthold D, Puranik P, Gantar M (2015) Screening of cyanobacteria and microalgae for their ability to synthesize silver nanoparticles with antibacterial activity. Biotechnology Reports 5: 112-119.

13. Greulich C, Diendorf J, Geßmann J, Simon T, Habijan T, et al. (2011) Cell typespecific responses of peripheral blood mononuclear cells to silver nanoparticles. Acta Biomaterialia. 7: 3505-3514.

14. Fabrega J, Luoma SN, Tyler CR, Galloway TS, Lead JR (2011) Silver nanoparticles: behaviour and effects in the aquatic environment. Environment International 37: 517-531.
15. Fayaz AM, Balaji K, Girilal M, Yadav R, Kalaichelvan PT, et al. (2010) Biogenic synthesis of silver nanoparticles and their synergistic effect with antibiotics: a study against gram-positive and gram-negative bacteria. Nanomedicine: Nanotechnology, Biology and Medicine 6: 103-109.

16. Singh R, Singh D (2014) Chitin membranes containing silver nanoparticles for wound dressing application. International Wound Journal 11: 264-268.

17. Zhang C, Hu Z, Deng B (2016) Silver nanoparticles in aquatic environments Physiochemical behavior and antimicrobial mechanisms. Water Research 88: 403-427.

18. Firdhouse MJ, Lalitha $\mathrm{P}$ (2015) Biosynthesis of silver nanoparticles and its applications. Journal of Nanotechnology 2015.

19. Chaloupka K, Malam Y, Seifalian AM (2010) Nanosilver as a new generation of nanoproduct in biomedical applications. Trends Biotechnol 28: 580-588. [Crossref]

20. Dubey P, Matai I, Kumar SU, Sachdev A, Bhushan B, et al. (2015) Perturbation of cellular mechanistic system by silver nanoparticle toxicity: Cytotoxic, genotoxic and epigenetic potentials. Advances in Colloid and Interface Science 221: 4-21.

21. Talapin DV, Lee JS, Kovalenko MV, Shevchenko EV (2010) Prospects of colloida nanocrystals for electronic and optoelectronic applications. Chem Rev 110: 389-458. [Crossref]

22. Rycenga M, Cobley CM, Zeng J, Li W, Moran CH, et al. (2011) Controlling the synthesis and assembly of silver nanostructures for plasmonic applications. Chemical Reviews 111: 3669-3712.

23. Amjadi M, Pichitpajongkit A, Lee S, Ryu S, Park I (2014) Highly stretchable and sensitive strain sensor based on silver nanowire-elastomer nanocomposite. ACS Nano 8: 5154-63.

24. Marradi M, Martín-Lomas M, PenadÉs S (2010) Glyconanoparticles: polyvalent tools to study carbohydrate-based interactions. Advances in Carbohydrate Chemistry and Biochemistry 64: 211-290.

25. Rabin O, Perez JM, Grimm J, Wojtkiewicz G, Weissleder R (2006) An X-ray computed tomography imaging agent based on long-circulating bismuth sulphide nanoparticles. Nature Materials 5: 118-122.

26. Jones MR, Osberg KD, Macfarlane RJ, Langille MR, Mirkin CA (2011) Templated techniques for the synthesis and assembly of plasmonic nanostructures. Chemical Reviews 111: 3736-827.

27. Byers CP, Hoener BS, Chang WS, Yorulmaz M, Link S, et al. (2014) Single-particle spectroscopy reveals heterogeneity in electrochemical tuning of the localized surface plasmon. The Journal of Physical Chemistry B 118: 14047-14055.

28. Zargar M, Shameli K, Najafi GR, Farahani F (2014) Plant mediated green biosynthesis of silver nanoparticles using Vitex negundo L. extract. Journal of Industrial and Engineering Chemistry 20: 4169-4175.

29. Scholl JA, Koh AL, Dionne JA (2012) Quantum plasmon resonances of individual metallic nanoparticles. Nature 483: 421-427. [Crossref]

30. Camden JP, Dieringer JA, Wang Y, Masiello DJ, Marks LD, et al. (2008) Probing the structure of single-molecule surface-enhanced Raman scattering hot spots. Journal of the American Chemical Society. 130: 12616-12617.

31. Pillai ZS, Kamat PV (2004) What factors control the size and shape of silver nanoparticles in the citrate ion reduction method?. The Journal of Physical Chemistry $B$ 108: 945-951.

32. Liu J, Sonshine DA, Shervani S, Hurt RH (2010) Controlled release of biologically active silver from nanosilver surfaces. ACS Nano 4: 6903-6913. [Crossref]

33. Ji X, Song X, Li J, Bai Y, Yang W, et al. (2007) Size control of gold nanocrystals in citrate reduction: the third role of citrate. J Am Chem Soc 129: 13939-13948. [Crossref]

34. Dong X, Ji X, Wu H, Zhao L, Li J, et al. (2009) Shape Control of Silver Nanoparticles by Stepwise Citrate Reduction. Journal of Physical Chemistry C 113: 6573-6576.

35. Sharma VK, Yngard RA, Lin Y (2009) Silver nanoparticles: green synthesis and their antimicrobial activities. Advances in Colloid and Interface Science 145: 83-96.

36. Linic S, Christopher P, Ingram DB (2011) Plasmonic-metal nanostructures for efficient conversion of solar to chemical energy. Nature Materials 10: 911-921.

37. Sharma VK, Yngard RA, Lin Y (2009) Silver nanoparticles: green synthesis and their antimicrobial activities. Advances in Colloid and Interface Science 145: 83-96.

38. Wiley B, Sun Y, Xia Y (2007) Synthesis of silver nanostructures with controlled shapes and properties. Acc Chem Res 40: 1067-1076. [Crossref]

39. Sperling RA, Parak WJ (2010) Surface modification, functionalization and bioconjugation of colloidal inorganic nanoparticles. Philosophical Transactions of the Royal Society of London A: Mathematical, Physical and Engineering Sciences 368: 1333-1383. 
40. Nakashima N, Yamanaka KI, Saeki M, Ohba H, Taniguchi S, et al. (2016) Metal ion reductions by femtosecond laser pulses with micro-Joule energy and their efficiencies. Journal of Photochemistry and Photobiology A: Chemistry 319: 70-77.

41. Guzman M, Dille J, Godet S (2012) Synthesis and antibacterial activity of silver nanoparticles against gram-positive and gram-negative bacteria. Nanomedicine: Nanotechnology, Biology and Medicine 8: 37-45.

42. Jones MR, Osberg KD, Macfarlane RJ, Langille MR, Mirkin CA (2011) Templated techniques for the synthesis and assembly of plasmonic nanostructures. Chem Rev 111: 3736-3827. [Crossref]

43. Kabashin A, Delaporte P, Pereira A, Grojo D, Torres R, et al. (2010) Nanofabrication with pulsed lasers. Nanoscale Res Lett 5: 454-463. [Crossref]

44. Sau TK, Rogach AL (2010) Nonspherical noble metal nanoparticles: colloid-chemical synthesis and morphology control. Advanced Materials 22: 1781-1804.

45. Langille MR, Personick ML, Zhang J, Mirkin CA (2012) Defining rules for the shape evolution of gold nanoparticles. J Am Chem Soc 134: 14542-14554. [Crossref]

46. Jin R, Cao Y, Mirkin CA, Kelly KL, Schatz GC, et al. (2001) Photoinduced conversion of silver nanospheres to nanoprisms. Science. 294: 1901-1903.

47. Shi JP, Ma CY, Xu B, Zhang HW, Yu CP (2012) Effect of light on toxicity of nanosilver to Tetrahymena pyriformis. Environmental Toxicology and Chemistry 31: 1630-1638.

48. Zhang Z, Li Q, Wu H, Zhang C, Cheng K, et al. (2015) Materials Chemistry. A Synthesis. 120:110-43.

49. Dreaden EC, Alkilany AM, Huang X, Murphy CJ, El-Sayed MA (2012) The golden age: gold nanoparticles for biomedicine. Chem Soc Rev 41: 2740-2779. [Crossref]

50. Khlebtsov NG, Dykman LA (2010) Optical properties and biomedical applications of plasmonic nanoparticles. Journal of Quantitative Spectroscopy and Radiative Transfer 111: 1-35.

51. Guerrero-Martínez A, Pérez-Juste J, Liz-Marzán LM (2010) Recent progress on silica coating of nanoparticles and related nanomaterials. Advanced materials. 22: 1182-1195.

52. Chaloupka K, Malam Y, Seifalian AM (2010) Nanosilver as a new generation of nanoproduct in biomedical applications. Trends Biotechnol 28: 580-588. [Crossref]

53. Thatai S, Khurana P, Boken J, Prasad S, Kumar D (2014) Nanoparticles and coreshell nanocomposite based new generation water remediation materials and analytical techniques: a review. Microchemical Journal. 116: 62-76.

54. El-Nour KM, Eftaiha AA, Al-Warthan A, Ammar RA (2010) Synthesis and applications of silver nanoparticles. Arabian Journal of Chemistry 3: 135-140.

55. Matin A, Khan Z, Zaidi SM, Boyce MC (2011) Biofouling in reverse osmosis membranes for seawater desalination: phenomena and prevention. Desalination 281: 1-6.

56. Lightcap IV, Kosel TH, Kamat PV (2010) Anchoring semiconductor and metal nanoparticles on a two-dimensional catalyst mat. Storing and shuttling electrons with reduced graphene oxide. Nano Letters 10: 577-583.

57. Zhu YJ, Chen F (2014) Microwave-assisted preparation of inorganic nanostructures in liquid phase. Chem Rev 114: 6462-6555. [Crossref]

58. Nadagouda MN, Speth TF, Varma RS (2011) Microwave-assisted green synthesis of silver nanostructures. Accounts of Chemical Research 44: 469-478.
59. Chen J, Wang K, Xin J, Jin Y (2008) Microwave-assisted green synthesis of silver nanoparticles by carboxymethyl cellulose sodium and silver nitrate. Mater Chem Phys 108: $421-424$.

60. Tolaymat TM, El Badawy AM, Genaidy A, Scheckel KG, Luxton TP, et al. (2010) An evidence-based environmental perspective of manufactured silver nanoparticle in syntheses and applications: a systematic review and critical appraisal of peer-reviewed scientific papers. Science of the Total Environment 408: 999-1006.

61. Narayanan KB, Sakthivel N (2010) Biological synthesis of metal nanoparticles by microbes. Adv Colloid Interface Sci 156: 1-13. [Crossref]

62. Xia Y, Xiao Z, Dou X, Huang H, Lu X, et al. (2013) Green and facile fabrication of hollow porous $\mathrm{MnO} / \mathrm{C}$ microspheres from microalgaes for lithium-ion batteries. ACS Nano 7: 7083-7092.

63. Narayanan KB, Sakthivel N (2010) Biological synthesis of metal nanoparticles by microbes. Adv Colloid Interface Sci 156: 1-13. [Crossref]

64. MubarakAli D, Thajuddin N, Jeganathan K, Gunasekaran M (2011) Plant extract mediated synthesis of silver and gold nanoparticles and its antibacterial activity against clinically isolated pathogens. Colloids and Surfaces B: Biointerfaces. 85: 360-365.

65. Armendariz V, Herrera I, Peralta-Videa JR, Jose-Yacaman M, Troiani H, et al. (2004) Size Controlled Gold Nanoparticle Formation by Avena sativa Biomass: Use of Plants in Nanobiotechnology. 129. Journal of Nanoparticle Research. 6: 377-382.

66. Gericke M, Pinches A (2006) Biological Synthesis of Metal Nanoparticles. Hydrometallurgy 83: 132-140.

67. Thakkar KN, Mhatre SS, Parikh RY (2010) Biological synthesis of metallic nanoparticles. Nanomedicine: Nanotechnology, Biology and Medicine 6: 257-262.

68. Guo R, Song Y, Wang G, Murray RW (2005) Does core size matter in the kinetics of ligand exchanges of monolayer-protected Au clusters? J Am Chem Soc 127: 27522757. [Crossref]

69. Daniel MC, Astruc D (2004) Gold nanoparticles: Assembly, supramolecular chemistry, quantum-size-related properties, and applications towards biology, catalysis, and nanotechnology. Chem Rev 104: 293-346.

70. Huang CC, Yang Z, Lee KH, Chang HT (2007) Synthesis of highly fluorescent gold nanoparticles for sensing mercury (II). Angew. Chem Int Ed. 46: 6824-6828.

71. Guo JZ, Cui H, Zhou W, Wang W (2008) Ag nanoparticle-catalyzed chemiluminescent reaction between luminal and hydrogen peroxide. J Photochem Photobiol. A: Chem 193: 89-96.

72. Brown LO, Hutchison JE (1997) Convenient preparation of stable, narrow-dispersity, gold nanocrystals by ligand exchange reactions. J Am Chem Soc 119: 12384-12385.

73. Aubin-Tam ME, Hamad-Schifferli K (2008) Structure and function of nanoparticleprotein conjugates. Biomedical Materials 3: 034001.

74. Ghosh P, Han G, De M, Kim CK, Rotello VM (2008) Gold nanoparticles in delivery applications. Adv Drug Deliv Rev 60: 1307-1315. [Crossref]

75. Dickerson EB, Dreaden EC, Huang X, El-Sayed IH, Chu H, et al. (2008) Gold nanorod assisted near-infrared plasmonic photothermal therapy (PPPT) of aquamous cell carcinoma in mice. Cancer Lett 269: 57-66.

Copyright: (C2017 Khatoon UT. This is an open-access article distributed under the terms of the Creative Commons Attribution License, which permits unrestricted use, distribution, and reproduction in any medium, provided the original author and source are credited. 